\title{
"Characteristics of patients admitted to emergency department for asthma attack: a real-LIFE study"
}

Laura Losappio ${ }^{1}$, Enrico Heffler ${ }^{2,3}$, Rossella Carpentiere ${ }^{4}$, Monica Fornero ${ }^{1}$, Cosimo Damiano Cannito ${ }^{4}$, Francesco Guerrera ${ }^{5}$, Francesca Puggioni ${ }^{2,3}$, Riccardo Monti ${ }^{6}$, Stefania Nicola ${ }^{6}$, Giovanni Rolla $^{6}$ and Luisa Brussino ${ }^{6^{*}}$ (D)

\begin{abstract}
Background: Asthma is a chronic disease affecting 30 million people in Europe under 45y. Poor control of Asthma is the main cause of emergency-department (ED) access, becoming the strongest determinant of the economic burden of asthma management.

Objective: To examine the characteristics of adult patients admitted to ED for acute asthma attack, focusing on previous diagnosis of asthma (DA) and current therapy.
\end{abstract}

Methods: During a one-year period, a structured questionnaire, assessing asthma diagnosis and management, was administered to all patients admitted for asthma attack, to the ED of a South-Italy town. Only patients with subsequently confirmed asthma were enrolled.

The data on oxygen saturation (Sat.O2), heart and respiratory-rate, severity code ED-admission, hospitalization or discharge, had been obtained.

Results: Two hundred one patients (mean 50.3ys), were enrolled. One hundred eighteen had a DA, made $17.5 \pm$ 5.88 years before, and $35.6 \%$ had a specialist-examination in the last year. $53.3 \%$ of DA-patients used a selfmedication before ED access with short-acting-beta-2-agonist and oral-corticosteroids, although none had a written-asthma-action-plan (WAAP). Almost all DA-patients were on regular therapy: inhaled-corticosteroids (ICS) in $61 \%$, associated with LABA in $85 \% .16 .7 \%$ of DA-patients had previous DA-access. The overall hospitalization-rate was 39\%, higher in DA compared to unknown asthmatic patients $(U A)(p=0.017)$.

Significant risk factors for hospitalization were Sat-O2 $\leq 94 \%$ breathing ambient air (OR9.91, $p<0.001$ ), inability-tocomplete a sentence $(\mathrm{OR} 9.42, \mathrm{p}<0.001)$ and the age $(\mathrm{OR} 1.02, p=0.049)$.

Conclusion: Despite the asthma guidelines-recommendation, up to $40 \%$ of patients received the asthma diagnosis in ED, only $61 \%$ of DA-patients were taking ICS. It is disappointing that DA-patients did not have a WAAP, which could explain the poor patient-self-medication at ED admission.

Keywords: Asthma attack, Asthma therapy, Adult asthma, Allergic asthma, Anti-asthmatic drugs

\footnotetext{
* Correspondence: luisa.brussino@unito.it

${ }^{6}$ Allergy and Clinical Immunology Unit, Department of Medical Science,

University of Torino and AO Ordine Mauriziano Umberto I, Torino, Italy

Full list of author information is available at the end of the article
}

(c) The Author(s). 2019 Open Access This article is distributed under the terms of the Creative Commons Attribution 4.0 International License (http://creativecommons.org/licenses/by/4.0/), which permits unrestricted use, distribution, and reproduction in any medium, provided you give appropriate credit to the original author(s) and the source, provide a link to the Creative Commons license, and indicate if changes were made. The Creative Commons Public Domain Dedication waiver (http://creativecommons.org/publicdomain/zero/1.0/) applies to the data made available in this article, unless otherwise stated. 


\section{Background}

Asthma is an important public health problem in Europe, affecting around 30 million children and adults under 45 years of age [1]. Estimates indicate that the age standardized hospital admission rate for asthma ranges from 30 to 70 per 100.000 Europeans older than 15 years, with an estimated economic burden of $€ 19.5$ billion annually $[1,2]$. The lack of disease control has been reported to be the strongest determinant of the individual total cost, which was 3-fold higher among uncontrolled subjects compared to controlled/partly controlled individuals, due to the increase in the indirect and hospital costs [3, 4]. Emergency department visits impose a heavy economic burden on health care, as each emergency visit costs 5 -fold more than outpatient visits for asthma [5]. Unfortunately, epidemiological surveys suggest that the control of asthma is still poor in the general population, mainly due to under-treatment of the disease [6-8].

Most emergency department (ED) visits for acute asthma are thought to be preventable [9], considering that the management of ED frequent attenders was found suboptimal according to guidelines [10].

Despite the heavy economic burden of asthma-related ED visits, few studies have been designed to characterize the asthmatic patients who attend ED for acute asthma. According to a large epidemiological study, primarily focused on the quality of emergency asthma care, the proportion of asthmatic patients taking inhaled corticosteroids as longterm control medication was only 35\% [11] and although the guidelines recommend the prescription of written asthma action plans (WAAP), their use remains limited $[12,13]$. The aim of the study was to examine the patient characteristics of adult patients admitted to the Emergency Department of Dimiccoli Hospital (the general hospital of Barletta, a 90,000 inhabitants town of South Italy) for an acute asthma attack, focusing on previous diagnosis of asthma and current asthma therapy.

\section{Methods}

All patients (age $\geq 12$ and $<65$ years) admitted to the ED for suspected acute asthma attack (ICD-9-CM 2012 Diagnosis Code: 493 as primary diagnosis) since 1st January 2013 until 31st December 2013 signed an informed consent form to participate in this study, which had been approved by the Local Ethic Committee.

A questionnaire was administered to all enrolled patients to obtain information about previous physician diagnosed asthma (DA) and current asthma medications, allergic rhinitis, outpatient visits for asthma and spirometry performed in the last 12 months, previous ED visits for asthma attack in the last 12 months, details of the medication used for asthma attack and whether the patients had received a written asthma action plan (WAAP) and comorbidities including allergic rhinitis were also assessed (Additional file 1). The duration of symptoms before the ED access was also considered. In this regard, the time lapse between the onset of the asthma attack and the ED attendance has been partitioned up to $6 \mathrm{~h}$, 6 to $24 \mathrm{~h}$ and more than $24 \mathrm{~h}$. Patients who had not previously received a diagnosis of asthma or who were not taking any medication for asthma, including inhalers, aerosol or tablets, were classified as possible unknown asthma. Every possible unknown asthmatic enrolled was evaluated by an Allergist/Pneumologist in the following months and was included in the final study population only if the diagnosis of asthma had been confirmed, according to GINA guidelines. These patients have been classified as "Unknown Asthma" (UA) at the ED admission.

Data on oxygen saturation, heart and respiratory rate, severity code admission at ED, ED course, and ED disposition about hospitalization or discharge, were obtained by chart review.

Statistical analysis was performed using a commercially available statistical package Stata 13.1 (Stata Corp LP, College Station, TX, USA), considering statistically significant only $p$ values $<0.05$. Data are given as means $\pm \mathrm{SD}$.

Three normality tests were performed (KolmogorovSmirnov, Shapiro-Wilk and D’Agostino's K-squared), to establish the distribution of the data. Basing on the normal or not normal distribution, the comparisons between clinical data from UA and DA patients, were performed using Student's t-test or Mann-Whitney U test.

The factors associated with a patient's admission were assessed with the use of logistic regression analysis. All factors associated with $p<0.10$ on univariable analysis were included in the multivariate model. All tests were two-sided, and variables were considered significant for $p$-values $<0.05$.

\section{Results}

Two hundred one patients had been admitted to the ED in 12 months, $126(62.7 \%)$ male and 75 (37.3\%) female, with a mean age 50.3 years (range $12-65$ yrs).

Of all the patients who were included, there were 118 (58.7\%) with DA and 83 (41.3\%) with UA. Clinical and demographic characteristics of the two groups are reported in Table 1.

In the group of DA patients, the diagnosis had been made 17,5 (95\%CI 14.8-19.9) years before, and 42 out of 118 (35.6\%) had a specialist examination in the last 12 months. Allergic rhinitis was reported by $54.2 \%$ of patients with DA and by $6 \%$ of patients with UA $(p<0.001)$. Concerning the time lapse between the onset of asthma attack and the ED access, a greater prevalence of ED access between the 6th and 24th hour was observed in DA patients $(62.7 \%)$ compared to UA patients $(44.6 \%, p=0.011)$, while no differences were observed in early access $(<6 \mathrm{~h})$, 
Table 1 - Clinical and demographic characteristics of the enrolled patients with previously diagnosed (DA) and not previously known (UA) asthma

\begin{tabular}{lll}
\hline Characteristics & DA $n=118$ & UA $n=83$ \\
\hline Male $\%$ & 61 & 65 \\
Mean age (range) & $50.3(12-64)$ & $46.4(12-65)$ \\
Specialist examination in the last 12 months $n(\%)$ & $42(35.6)$ & - \\
Rhinitis $n(\%)$ & $64(54,2)$ & $5(6) \quad \mathrm{ns}<0.001$ \\
\hline
\end{tabular}

Male \%: percentage of male enrolled to the study. Mean age (range): mean age of people enrolled to the study. Specialist examination in the last 12 months: number of people who consulted a specialist in the last 12 months. Rhinitis $n$ (\%): percentage of people affected by rhinitis

respectively 21,2 and $30,2 \%$, and in late access (> 24h), respectively 12.7 and $20.5 \%$.

Sixty-three DA patients (53.3\% of all DA patients) used self-medication before the ED access, consisting of short-acting beta-2 agonist (SABA) in 57 of them (90\%) and oral corticosteroids in $6(10 \%)$, according to their physicians' advice. No patient had a WAAP and none used peak flow assessment.

Almost all the DA patients (112/118, 94.9\%) were on regular therapy, consisting of inhaled corticosteroids (ICS) in 68/112 (60.71\%), associated with LABA in $85 \%$ of them, SABA alone in 14 patients (12.5\%), antihistamines for associated allergic rhinitis in $25(22 \%)$, oral corticosteroids (OCS) in $4(3,5 \%)$ and theophylline in one patient $(0,9 \%)$.

Twenty DA patients (16.9\%) had an history of previous ED access during the last 12 months. Among these patients, $14(70 \%)$ had at least one specialist examination in the last 12 months, 18 (90\%) received regular treatment with ICS, combined with LABA in $78 \%$, while two patients $(10 \%)$ were taking only antihistamine drugs for concomitant rhinitis.

The hospitalization rate after acute admission in ED was $38.8 \%(78 / 201)$ for the whole study population, significantly higher in DA compared to UA patients (64 and $36 \%$ respectively, $p=0.017$ ).

Clinical and demographic characteristics of hospitalized patients (HP) compared to patients who were discharged are reported in Table 2. Patients who were hospitalized were older (60.8 vs 43.5 yrs., $p<0.001$ ), had higher prevalence of previous diagnosis of asthma (64.1 vs $55 \%, p=0.009)$ and previous ED visits $(16.7 \%$ vs $11.4 \%, \mathrm{p}=0.01$ ), lower $\mathrm{SaO} 2$ (89.8 vs $96.1 \%, \mathrm{p}<0.001$ ), higher respiratory rate $(22 \pm 4$ vs $18.5 \pm 2.8, \mathrm{p}<0.001)$ and pulse rate $(85.4 \pm 15$ vs $80.3 \pm 13, p=0.004)$, and they were more frequently unable to complete a sentence $(67.95$ vs $13.8 \%, \mathrm{p}<0.001)$.

Multivariate analysis (Table 3) showed that independent significant risk factors for hospitalization were oxygen saturation lower than $94 \%$ at breathing air (OR 9.91, $p<0.0001$ ), the inability to complete a sentence (OR 9.42, $\mathrm{p}<0.0001)$ and the age of the patients (OR 1.02, $p=0.049)$.

\section{Discussion}

A surprising result of our study was that $40 \%$ of patients presenting to the ED received the diagnosis of asthma for the first time. It is known that asthma may be

Table 2 - Risk factors determining the hospitalization (201 patients)

\begin{tabular}{|c|c|c|c|}
\hline & $\begin{array}{l}\text { Hospitalized patients } \\
\text { (n 78) }\end{array}$ & Discharged patients (n 123) & $\mathrm{p}=$ \\
\hline Age - years (range) & $60.8(12-65)$ & $43.5(12-63)$ & $<0.001$ \\
\hline $\mathrm{DA}(\%)$ & 64.1 & 55 & 0.009 \\
\hline$\geq 1$ ED admission (\%) & 16.7 & 11.4 & 0.010 \\
\hline $\mathrm{SaO} 2 \%(\mathrm{SD})$ & $89.8(8.09)$ & $96.1(2.74)$ & $<0.001$ \\
\hline Respiratory rate (SD) & $22(3.97)$ & $18.53(2.76)$ & $<0.001$ \\
\hline Pulse rate (SD) & $85.4(15.01)$ & $80.33(13.04)$ & 0.004 \\
\hline Years from diagnosis (SD) & $14.53(5.88)$ & $7.41(11.26)$ & Ns \\
\hline ED admission code (\%) & $\begin{array}{l}\text { Green } 15.4 \% \\
\text { Yellow } 64.1 \% \\
\text { Red } 20.5 \%\end{array}$ & $\begin{array}{l}\text { Green } 57.7 \% \\
\text { Yellow } 42.3 \%\end{array}$ & $<0.001$ \\
\hline Inability to complete a sentence (\%) & 67.95 & 13.82 & $<0.001$ \\
\hline
\end{tabular}

Age - yrs. (range): mean age of the two considered groups. DA (\%): percentage of patients with previous asthma diagnosis. $\geq 1 \mathrm{ED}$ admission (\%): percentage of patients with more than one ED admission in the last 12 months. SaO2\% (SD): mean pulse oximetry at ED visit. Respiratory rate (SD): mean values of respiratory rate at ED visit. Pulse rate (SD): mean values of pulse rate at ED visit. Years from diagnosis (SD): numbers of years since the diagnosis of asthma. ED admission code (\%): index of disease severity (green: low severity; yellow: medium severity; red: emergency). Inability to complete a sentence (\%): percentage of people who could not complete a sentence due to dyspnea 
Table 3 - Multivariate analysis of risk factor affecting the hospitalization (193 Patients)

\begin{tabular}{lll}
\hline Variable & Odd Ratio $[95 \% \mathrm{Cl}]$ & $\mathrm{p}=$ \\
\hline Age & $1.02[1.01-1.05]$ & 0.049 \\
Years from diagnosis (SD) & $1.00[0.97-1.05]$ & $\mathrm{ns}$ \\
Time lapse $<6 \mathrm{~h}$ & $0.80[0.28-2.33]$ & $\mathrm{ns}$ \\
$6-24 \mathrm{~h}$ & $0.81[0.29-2.31]$ & $\mathrm{ns}$ \\
$>24 \mathrm{~h}$ & $1.2[0.31-4.74]$ & $\mathrm{ns}$ \\
$\mathrm{SaO} 2 \leq 94$ & $9.91[3.83-25.6]$ & $<0.0001$ \\
Respiratory rate $\geq 18 /$ min & $2.99[0.78-11.5]$ & $\mathrm{ns}$ \\
Inability to complete a sentence & $9.42[3.60-24.7]$ & $<0.0001$
\end{tabular}

Age: mean age of patients hospitalized or not. Lenght from Diagnosis: years since diagnosis of asthma. Time lapse $<6 \mathrm{~h}$ : less than $6 \mathrm{~h}$ between symptoms onset and ED admission. 6-24 h: 6 to $24 \mathrm{~h}$ between symptoms onset and ED admission. $>24 \mathrm{~h}$ : more than $24 \mathrm{~h}$ between symptoms onset and ED admission. $\mathrm{SaO} 2<=94$ : pulse oximetry at ED visit less than $94 \%$ on air (FiO2 $21 \%$ ). Respiratory rate $\geq 18 / \mathrm{min}$ : respiratory rate more than 18 acts per minute

diagnosed for the first time in a patient presenting to the $\mathrm{ED}$, but, in the majority of cases, the patient will be aware of the underlying diagnosis of asthma [14].

A confident diagnosis of asthma cannot be made on a single visit to the ED, (particularly in children and in older patients, who were not enrolled in our study) and the mis-diagnosis of asthma is also frequent in patients managed in primary care settings $[15,16]$. Many conditions that may mimic asthma acutely had been considered and excluded in our patients, such as pulmonary embolism, heart failure or hyperventilation syndrome. In all these patients the diagnosis of asthma was confirmed by a specialist during the follow-up visits after Hospital discharge. It appears that, for many patients, asthmatic symptoms are not considered serious enough to be reported to their general practitioner, until an acute asthma attack occurs, which forces them to go to the emergency department. The only difference between patients with UA compared to patients with DA was the prevalence of rhinitis, which was reported only in $6 \%$ of the UA patients compared to $54 \%$ of DA. Rhinitis comorbidity may lead the patients with asthmatic symptoms to be evaluated by their physicians for asthmatic symptoms earlier than the patients without rhinitis.

Inhaled corticosteroids were regularly used by $60 \%$ of our patients with DA, a percentage higher than the percentage previously reported in patients admitted to ED for asthma, which had been reported as low as $35 \%$ in a US large epidemiological study primarily focused on the quality of emergency asthma care during exacerbation [11]. Indeed, despite an increase in the consumption of inhaled corticosteroids (ICS), their use is still inadequate, since five out of 10 asthmatic patients were using a medication regimen below their disease severity level, according to an Italian epidemiologic study and the inadequate dosing of ICS was found to be the main predictor of the poor control of the disease in the same study [6].

High use of health services, including ED visits, has been observed in patients with suboptimal asthma drug regimens in a Canadian population-based assessment study [17]. In particular, adolescents with suboptimal regimens were the most likely to have hospital admissions (odds ratio (OR) 3.8; 95\% confidence interval (CI) 1.87.8), visit the ED (OR 2.2; 95\% CI 1.6-3.1) and be high users of family physician services (OR 5.7; 95\% CI 4.0-8.1) compared with patients in other age groups. Recently the diagnosis of asthma has been reported in $12.7 \%$ of patients who presented to an Emergency Department in the Asia Pacific region with a principal symptom of dyspnea [18]. Over $90 \%$ of these patients had received a previous diagnosis of asthma, but only $40 \%$ of them used inhaled corticosteroids as regular treatment. In our study, up to $90 \%$ of the patients who had been previously admitted to ED for asthma exacerbation used ICS and most of them had had a specialist visit for their asthma in the last 12 months, compared to only $35 \%$ of the other patients. In our patients the reasons for frequently attending ED seemed to be found in the severity of asthma and not in socioeconomic factors, as reported in a US study [19]. It is disappointing that no patient with DA had a written asthma action plan for managing asthma exacerbation. This explains why only $60 \%$ of the patients used self-administered medication before their admission at ED.

In conclusion, despite guideline recommendations about asthma diagnosis and treatment, up to $40 \%$ of patients presenting to the ED received the diagnosis of asthma for the first time, and ICS were regularly used only by $60 \%$ of patients with known asthma. Moreover, it is disappointing that none of the patients had a WAAP. This could explain why only $53 \%$ of the patients used self- administered medication before their attendance at the ED.

\section{Conclusions}

Despite asthma guidelines-recommendation, up to $40 \%$ of patients received the asthma diagnosis in ED, only $61 \%$ of DA-patients were taking ICS. It is disappointing that DA-patients did not have a WAAP, which could explain the poor patient-self-medication at ED admission.

\section{Additional file}

Additional file 1: "Asthma questionnaire - Emergency Department admission due to asthma attack" Description of data: the questionnaire contains data assessing asthma diagnosis and management, primary vital signs and drugs administered in Emergency Department (ED) in patients admitted to the ED for an acute asthma attack. (DOCX $15 \mathrm{~kb}$ )

\section{Abbreviations}

Cl: Confidence Interval; DA: Previous Diagnosis Of Asthma; ED: EmergencyDepartment; GINA: Global Initiative For Asthma; HP: Hospitalized Patients; 
ICS: Inhaled-Corticosteroids; LABA: Long Acting Beta 2 Agonists; OR: Odd Ratio; SABA: Short-Acting Beta-2 Agonist; Sat.O2: Oxygen Saturation; UA: Undiagnosed Asthma; WAAP: Written-Asthma-Action-Plan

\section{Acknowledgements}

Not Applicable.

\section{Authors' contributions}

LL: data acquisition. EH: study design, manuscript drafting, critical manuscript revision. RC: data acquisition. MF: data acquisition, data analysis, critical manuscript revision. CDC: data acquisition. FG: data analysis. FP: manuscript drafting, critical manuscript revision. RM: data analysis. SN: study design, manuscript drafting, critical manuscript revision. GR: study design, manuscript drafting, critical manuscript revision. LB: study design, manuscript drafting, critical manuscript revision. All Authors have approved the submitted version (and any substantially modified version that involves the author's contribution to the study). All Authors have agreed both to be personally accountable for the author's own contributions and to ensure that questions related to the accuracy or integrity of any part of the work, even ones in which the author was not personally involved, are appropriately investigated, resolved, and the resolution documented in the literature.

\section{Funding}

No funding was obtained for this study.

\section{Availability of data and materials}

The datasets generated and analyzed during the current study are not publicly available due to the uncomplete use of them and to the possibility of further studies, but are available from the corresponding author on reasonable request.

\section{Ethics approval and consent to participate}

All patients signed an informed consent to participate to this study. Written informed consent to publish this information was also obtained from the parents or guardia of minor participants.

Full name of the ethics committee: "Comitato Etico Aziendale Ospedale Mons. Dimiccoli - Barletta (BT), Italy". Trial registration: 20130503. Date of registration: 03 may 2013. Date of enrolment of the first participant to the trial: 06 may 2013.

\section{Consent for publication}

Not Applicable.

\section{Competing interests}

The authors declare that they have no competing interests.

\section{Author details}

'Allergy and Immunology Department, Niguarda Ca Granda Hospital, Milan, Italy. ${ }^{2}$ Personalized Medicine, Asthma and Allergy, Humanitas Research Hospital, Rozzano, Italy. ${ }^{3}$ Department of Biomedical Sciences, Humanitas University, Rozzano, Italy. ${ }^{4}$ Emergency Department, "Dimiccoli" Hospital, Barletta, Italy. ${ }^{5}$ Department of Surgical Science, University of Torino, Torino, Italy. ${ }^{6}$ Allergy and Clinical Immunology Unit, Department of Medical Science, University of Torino and AO Ordine Mauriziano Umberto I, Torino, Italy.

\section{Received: 24 January 2019 Accepted: 6 June 2019}

\section{Published online: 17 June 2019}

\section{References}

1. Lung health in Europe FACTS \& FIGURES. A better understanding of lung disease and respiratory care in Europe. European Respiratory Society. The European lung white book. 2013

2. Nunes C, Pereira AM, Morais-Almeida M. Asthma costs and social impact. Asthma Res Pract. 2017;(3):1. https://doi.org/10.1186/s40733-016-0029-3.

3. Bahadori K, Doyle-Waters MM, Marra C, Lynd L, Alasaly K, Swiston J, FitzGerald JM. Economic burden of asthma: a systematic review. BMC Pulm Med. 2009:9:24. https://doi.org/10.1186/1471-2466-9-24.

4. Vervloet D, Williams AE, Lloyd A, Clark TJH. Costs of managing asthma as defined by a derived asthma control test TM score in seven European countries. Eur Respir Rev. 2006;15(98):17-23.
5. Accordini S, Corsico AG, Braggion M, Gerbase MW, Gislason D, Gulsvik A, Heinrich J, Janson C, Javvis D, Jögi R, Pin I, Schoefer Y, Bugiani M, Cazzoletti L, Cerveri I, Marcon A, de Marco R. The cost of persistent asthma in Europe: an international population-based study in adults. Int Arch Allergy Immunol. 2013;160(1):93-101.

6. De Marco R, Bugiani M, Cazzoletti L, Carosso A, Accordini S, Buriani O, Carrozzi L, Dallari R, Giammanco G, Ginesu F, Marinoni A, Lo Cascio V, Poli A, Struzzo P, Janson C; ISAYA study group. The control of asthma in Italy. A multicentre descriptive study on young adults with doctor diagnosed current asthma. Allergy 2003; 58: 221-228.

7. Rabe KF, Vermeire PA, Soriano JB, Maier WC. Clinical management of asthma in 1999: the asthma insights and reality in Europe (AIRE) study. Eur Respir J. 2000;16:802-7.

8. Vermeire PA, Rabe KF, Soriano JB, Maier WC. Asthma control and differences in management practices across seven European countries. Respir Med. 2002:96(3):142-9.

9. Griswold SK, Nordstrom CR, Clark S, Gaeta TJ, Price ML, Camargo CA Jr. Asthma exacerbations in north American adults: who are the "frequent fliers" in the emergency department? Chest 2005; 127:1579-1586.

10. Hasegawa K, Sullivan AF, Hirashima T. Gaeta TJ, fee C, Turner SJ, Massaro S, Camargo CA Jr. multicenter airway research Collaboration-36 investigators. A multicenter observational study of US adults with acute asthma: who are the frequent users of the emergency department? J Allergy Clin Immunol Pract. 2014;2(6):733-40

11. Hasegawa K, Sullivan AF, Tsugawa Y, Turner SJ, Massaro S, Clark S, Tsai CL, Camargo CA Jr; MARK-36 Investigators. Comparison of US emergency department acute asthma care quality: 1997-2001 and 2011-2012 J Allergy Clin Immunol 2015; 135 (1): 73-80.

12. Eguienta S, Fayon M. Prescription of asthma action plans in the Aquitaine region of France. Rev Mal Respir. 2016;33:365-76.

13. Centers for Disease Control and Prevention (CDC). Vital signs: asthma prevalence, disease characteristics, and self-management education: United States, 2001--2009. MMWR Morb Mortal Wkly Rep. 2011;60(17):547-52.

14. Adams JY, Sutter ME, Albertson TE. The patient with asthma in the emergency department. Clinic Rev Allerg Immunol. 2012;43(1-2):14-29.

15. Heffler E, Pizzimenti S, Guida G, Bucca C, Rolla G. Prevalence of over-misdiagnosis of asthma in patients referred to an allergy clinic. J Asthma. 2015;52(9):931-4.

16. Heffler E, Crimi C, Mancuso S, Campisi R, Puggioni F, Brussino L, Crimi N. Misdiagnosis of asthma and COPD and underuse of spirometry in primary care unselected patients. Respir Med. 2018;142:48-52.

17. Zhang T, Smith MA, Camp PG, Carleton BC. High use of health services in patients with suboptimal asthma drug regimens: a population-based assessment in British Columbia, Canada. Pharmacoepidemiol Drug Saf. 2013;22:744-51.

18. Kuan WS, Craig S, Kelly AM, Keijzers G, Klim S, Graham CA, Jones P, Holdgate A, Lawoko C, Laribi S. Asthma among adult patients presenting with dyspnea to the emergency department: an observational study. Clin Respir J. 2018. https://doi.org/10.1111/cri.12782 [Epub ahead of print].

19. Hasegawa K, Tsugawa Y, Brown DF, Camargo CA Jr. A population-based study of adults who frequently visit the emergency Department for Acute Asthma California and Florida, 2009-2010. Ann Am Thorac Soc 2014; 11(2):158-163.

\section{Publisher's Note}

Springer Nature remains neutral with regard to jurisdictional claims in published maps and institutional affiliations.

Ready to submit your research? Choose BMC and benefit from:

- fast, convenient online submission

- thorough peer review by experienced researchers in your field

- rapid publication on acceptance

- support for research data, including large and complex data types

- gold Open Access which fosters wider collaboration and increased citations

- maximum visibility for your research: over $100 \mathrm{M}$ website views per year

At $\mathrm{BMC}$, research is always in progress.

Learn more biomedcentral.com/submissions 